\title{
Effect of Temperature and Time on the Kraft Pulping of Egyptian Bagasse
}

\author{
Mohamed Bassiouni Morsy Ghazy \\ Chemistry department, faculty of science, Al-Azhar University, Nasr city, Cairo, Egypt
}

\begin{abstract}
The objective of the investigation is to study the influence of temperature and time on the kraft pulping of Egyptian bagasse and to verify the application of kinetics for the rate of delignification. The bagasse suffers much loss during the heating period in which the yield is $62-60.8 \%$ while after 150 min of cooking reached $59.8-58 \%$ at $160-180^{\circ} \mathrm{C}$, respectively. The lignin content decreases from 6.9-5.76 \% through temperature elevation to $5.39-4.01 \%$ after $150 \mathrm{~min}$ of pulping at $160-180{ }^{\circ} \mathrm{C}$, respectively. Holocellulose data shows an inflection point after 90 min.
\end{abstract}

Keywords: Bagasse, kraft Pulping, Kinetics, Delignification, Activation Energy, Selectivity

\section{Introduction}

Sugarcane bagasse (SCB), one of the largest cellulosic agroindustrial by-products of the sugar and alcohol industry, is a renewable resource with short regenerable cycle [1]. It is the second most commonly used non-wood fiber plant material for pulp and paper production in many parts of the world, including South Africa, Central Asia, the Middle East and North America [2]. The main argument in support of using bagasse as a raw material is its ready availability as a residue from sugarcane, together with the fact that protective measures being adopted to prevent the indiscriminate cutting of wood mean that the paper industry is facing a shortage of wood material [3]. Besides its availability, SCB is characterized by high cellulose (40-50\%), and hemicelluloses content (xylan: 28-30\%), but lower lignin content (19-21\%), compared with other wood feedstocks, such as Eucalyptus or Pine, generally used for pulp and paper production [4,5]. Because of its lower lignin content, SCB is more easily delignified, requiring milder and shorter cooking conditions than wood sources [6]. Another interesting feature of SCB is its lower silica (a component of ash) compared with wood and other nonwood fibers [6].

Kraft pulping is an alkaline process that utilizes $\mathrm{NaOH}$ and $\mathrm{Na}_{2} \mathrm{~S}$ as active chemicals in the liquor to degrade the lignin and to liberate the fibers. The process is a complex procedure which involves several reactions and much work has been made trying to establish kinetics of the participating compounds. The delignification proceeds through the cleavage of $\beta$-aryl ether linkages which degrades the lignin, then it could be dissolved. The kraft process is heterogeneous delignification reaction consists of three key kinetic steps: (1) adsorption of hydroxide and hydrosulfide ions on lignin; (2) surface reaction on the solid surface to produce degraded lignin products; and (3) desorption of degradation products from the solid surface [7]. The kraft delignification process can be divided into three distinct phases. The initial phase takes place as the temperature rises to $140{ }^{0} \mathrm{C}$ [8] and is controlled by diffusion [9]. In this phase about $20 \%$ of lignin is removed. While the bulk phase begins above $140{ }^{\circ} \mathrm{C}$ in which the rate of delignification becomes controlled by chemical reactions and accelerates steadily with increasing temperature.

The rate of lignin dissolution remains high until about $90 \%$ of the lignin has been removed. The slow residual delignification phase is related to the removal of condensed lignin units and is affected by the alkali charge and the cooking temperature. The kraft pulping have an adverse effect on carbohydrates, causing a direct dissolution of the low-molecular polysaccharide fractions by the alkaline reaction solution under elevated temperatures and a substantial degradation and modification of the residual polysaccharides [10]. In a typical kraft cook more than $90 \%$ of lignin is removed compared with about $30 \%$ of carbohydrates loss. The final yield is normally within 45-65 $\%$ depending on the extent of the cook [11].

The aim of this work is to study the effect of cooking temperature and time on the rate of delignification as well as the chemical constitution of Egyptian bagasse during kraft pulping.

\section{Experimental}

\subsection{Materials}

The depithed bagasse used in this research was delivered from Masr-Edfu pulp mill at Aswan - Egypt. Sodium hydroxide $(\mathrm{NaOH})$ is obtained from el-Naser pharmaceutical chemical company, Egypt and sodium sulfide $\left(\mathrm{Na}_{2} \mathrm{~S}\right)$ is obtained from oxford laboratory reagent, India while sodium chlorite $\left(\mathrm{NaClO}_{2}\right)$ is delivered from AL- gomhoreya pharmaceutical chemical company, Egypt.

\subsection{Kraft Pulping}

For each experiment, $10 \mathrm{~g}$ oven dried bagasse was pulped with $40 \mathrm{ml}$ white liquor containing $20 \% \mathrm{NaOH}$ and $20 \%$ $\mathrm{Na}_{2} \mathrm{~S}$ based on oven dried bagasse in $250 \mathrm{ml}$ stainless steel autoclave (bomb) at different temperatures (160-165-170$175-180{ }^{\circ} \mathrm{C}$ ) and time intervals ( $0,30,60,90,120$ and 150 min). The time is calculated from the elevated temperatures. After mixing the bagasse with the cooking liquor; the bombs were purged with nitrogen, sealed and immersed in oil bath 


\section{International Journal of Science and Research (IJSR) \\ ISSN (Online): 2319-7064}

Index Copernicus Value (2013): 6.14 | Impact Factor (2014): 5.611

then, heated up to the desired temperature. After cooking, the pressure was released, the bombs were opened, filtered off and the black liquor was collected for $\mathrm{pH}$ measurement. While the pulp was washed several times with tap water till free of black liquor, disintegrated and then air dried. Every experiment was repeated and mixed well to get enough pulp for chemical analysis. The $\alpha$ - cellulose, yield, one percent sodium hydroxide solubility, insoluble lignin and kappa number of pulp samples were determined according to Tappi test methods T203, T210, T212, T222 and T236, respectively. While, holocellulose, acid soluble lignin and ash content were determined according to wise [12], Tappi useful method UM 250 and T211, respectively.

\section{Results and discussion}

\subsection{Chemical analysis of bagasse}

Table 1 Chemical analysis of bagasse.

\begin{tabular}{|c|c|c|c|}
\hline Holocellulose \% & $\alpha$-cellulose \% & Total lignin \% & Ash \% \\
\hline 78 & 59 & 20 & 1.75 \\
\hline
\end{tabular}

The chemical analysis of bagasse Table (1) was determined previously [13].

\subsection{Time Temperature dependence of kraft delignificat- ion}

The kraft pulping was selected over the soda cooking because of the higher pulp yield of the former process [14]. Bagasse pulps have properties normally considered similar, or a little inferior, to those of hardwood pulps [15]. When bagasse is mixed with the cooking chemicals, the reaction between chemicals and lignocellulosic components in bagasse initiated at certain number of reactive sites that are exposed to the cooking chemicals [16] which could be on the surface or interior of bagasse. The cooking liquor reacts with the lignocellulosic components causing dissolution of some of these components resulting in openings that allow the chemicals to penetrate the bagasse structure. As the pulping process proceeds this results in further decomposition of bagasse components and transformation of the bagasse structure. The pulping reactions start to spread from the initial reactive sites of bagasse. The resultant spread depends not only on the chemical composition of bagasse, but also on the heterogeneity of its structure and the time of reaction. It may be assumed that the number of reactive sites involved at the beginning of the pulping process depends on the cooking temperature and the bulk chemical concentration surrounding the bagasse.

The chemical analysis of the kraft pulp samples at different times and temperatures are compiled in Table (2) and graphically represented in figures (1-5). Fig (1) shows that the pulp yield decreased as the time of cooking proceeds as well as raising the temperature. This reduction is due to carbohydrate degradation and dissolution (17) and lignin removal (14).

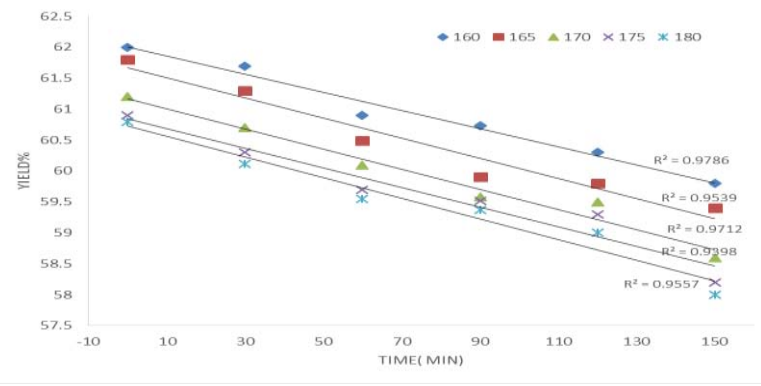

Figure 1: Effect of temperature and time of cooking on the yield \%.

Vaaler ${ }^{(18)}$ mentioned that peeling and dissolution of low molecular mass carbohydrates in alkali are the main reasons for yield loss in kraft cooking. A straight line relationship with good correlation $\left(\mathrm{R}^{2}=0.94\right.$ - 0.98$)$ was observed for the variation of yield with time at different temperatures. The yield loss of bagasse kraft pulp at $170{ }^{0} \mathrm{C}$ for 150 min was $41.4 \%$ comparing to $42.2 \%$ in a previous study [13].

The initial $\mathrm{pH}$ of the white liquor is higher than 12.6 while the final $\mathrm{pH}$ lies between 10.9 to 10.3 depending on the temperature and time of pulping. The intimate contact of hydroxide ions with wood (or bagasse) components immediately leads to deacetylation reactions [19] while pulping causes carbohydrate degradation forming hydroxy acids which lower the $\mathrm{pH}$ [20]. As a result of the alkaline degradation of polysaccharides, about 1.6 equivalents of acids are formed for every monosaccharide unit peeled from the chain. Of the charged alkali, $60-70 \%$ is required for the neutralization of these hydroxy acids, while the rest is consumed to neutralize uronic and acetic acids and degradation products of lignin [9].

Fig (2) refers to the effect of time and temperature on polysaccharides; holocellulose (a) and $\alpha$ cellulose (b); in which the carbohydrates are degraded due to peeling and hydrolysis. The peeling starts at low temperature and proceeds with pulping extension. But at higher temperatures an alkaline hydrolysis of glycosidic bonds with random scission and polysaccharide macromolecules takes place, thereby allowing secondary peeling reactions [21,22].

Holocellulose data shows an inflection point after 90 minutes which may be due to the transition between bulk and residual phases in which the degradation begins fast then slow down with the time. On the other hand, cellulose is peeled off during pulping and this peeling reactions; which are responsible for the cellulose loss; are more sensitive to the temperature change than the cleavage reactions which is responsible for the loss of pulp viscosity [23]. This cellulose loss increases as the temperature raised and time proceeded because the temperature and pressure have major effects on the crystalline structure of cellulose during cooking [24]. Hot $1 \%$ alkali solubility extracts the low molecular weight carbohydrates indicating the extent of cellulose degradation during pulping. As shown in Fig (3) the values of alkali solubility decreases with the increase of cooking time and temperature due to solubilization of the peeled cellulose products. 
International Journal of Science and Research (IJSR)
ISSN (Online): 2319-7064

Index Copernicus Value (2013): 6.14 | Impact Factor (2014): 5.611

a

$\mathrm{b}$

Figure 2: Effect of temperature and time of cooking on holocellulose (a) and $\alpha$-cellulose (b).

Table 2: Chemical analysis of kraft pulp samples

\begin{tabular}{|c|c|c|c|c|c|c|c|}
\hline & Time (min) & 0 & 30 & 60 & 90 & 120 & 150 \\
\hline \multirow{5}{*}{ Yield \% } & $160^{\circ} \mathrm{C}$ & 62.00 & 61.70 & 60.90 & 60.73 & 60.30 & 59.80 \\
\hline & $165^{\circ} \mathrm{C}$ & 61.80 & 61.30 & 60.49 & 59.90 & 59.80 & 59.40 \\
\hline & $170^{\circ} \mathrm{C}$ & 61.20 & 60.70 & 60.09 & 59.58 & 59.50 & 58.60 \\
\hline & $175^{0} \mathrm{C}$ & 60.90 & 60.30 & 59.70 & 59.52 & 59.30 & 58.20 \\
\hline & $180^{\circ} \mathrm{C}$ & 60.80 & 60.11 & 59.55 & 59.37 & 59.01 & 58.00 \\
\hline \multirow{5}{*}{ Holocellulose \% } & $160^{\circ} \mathrm{C}$ & 93.20 & 92.80 & 92.60 & 91.25 & 90.40 & 90.00 \\
\hline & $165^{0} \mathrm{C}$ & 92.90 & 91.70 & 91.55 & 90.45 & 89.40 & 89.60 \\
\hline & $170^{\circ} \mathrm{C}$ & 90.60 & 91.00 & 89.85 & 88.34 & 88.00 & 87.65 \\
\hline & $175^{0} \mathrm{C}$ & 91.60 & 89.25 & 88.78 & 87.60 & 87.20 & 86.24 \\
\hline & $180^{\circ} \mathrm{C}$ & 89.65 & 89.30 & 87.40 & 85.90 & 86.25 & 84.29 \\
\hline \multirow{5}{*}{$\alpha$-cellulose $\%$} & $160^{\circ} \mathrm{C}$ & 71.20 & 71.40 & 70.50 & 70.00 & 68.90 & 67.80 \\
\hline & $165^{0} \mathrm{C}$ & 70.40 & 68.40 & 67.21 & 66.16 & 66.12 & 65.40 \\
\hline & $170^{0} \mathrm{C}$ & 70.00 & 70.62 & 67.40 & 65.80 & 63.16 & 63.18 \\
\hline & $175^{0} \mathrm{C}$ & 68.87 & 66.90 & 65.65 & 64.20 & 64.80 & 62.85 \\
\hline & $180^{\circ} \mathrm{C}$ & 68.30 & 67.60 & 63.07 & 64.11 & 61.43 & 59.85 \\
\hline \multirow{5}{*}{ Lignin \% } & $160^{\circ} \mathrm{C}$ & 6.90 & 6.55 & 6.20 & 6.12 & 5.66 & 5.39 \\
\hline & $165^{\circ} \mathrm{C}$ & 6.70 & 6.42 & 6.10 & 5.72 & 5.60 & 5.25 \\
\hline & $170^{\circ} \mathrm{C}$ & 6.48 & 5.90 & 5.55 & 5.33 & 5.20 & 4.95 \\
\hline & $175^{0} \mathrm{C}$ & 6.32 & 5.36 & 5.27 & 5.04 & 4.80 & 4.56 \\
\hline & $180^{\circ} \mathrm{C}$ & 5.76 & 5.38 & 4.90 & 4.51 & 4.26 & 4.01 \\
\hline \multirow{5}{*}{ Карра по. } & $160^{\circ} \mathrm{C}$ & 56.40 & 53.60 & 52.00 & 50.80 & 47.76 & 45.40 \\
\hline & $165^{0} \mathrm{C}$ & 54.50 & 52.60 & 50.30 & 48.15 & 45.00 & 44.60 \\
\hline & $170^{\circ} \mathrm{C}$ & 53.20 & 49.00 & 47.80 & 46.35 & 44.60 & 43.00 \\
\hline & $175^{0} \mathrm{C}$ & 52.30 & 48.64 & 46.16 & 43.60 & 42.00 & 40.38 \\
\hline & $180^{\circ} \mathrm{C}$ & 49.40 & 46.90 & 42.68 & 40.04 & 38.40 & 37.00 \\
\hline \multirow{5}{*}{$1 \%$ alkali soluble } & $160^{\circ} \mathrm{C}$ & 24.44 & 23.40 & 23.00 & 22.40 & 21.67 & 19.99 \\
\hline & $165^{0} \mathrm{C}$ & 21.30 & 20.80 & 19.80 & 19.20 & 19.65 & 19.05 \\
\hline & $170^{\circ} \mathrm{C}$ & 19.24 & 18.67 & 17.70 & 17.50 & 16.90 & 16.40 \\
\hline & $175^{0} \mathrm{C}$ & 17.04 & 16.48 & 15.80 & 14.50 & 15.10 & 14.60 \\
\hline & $180^{\circ} \mathrm{C}$ & 16.09 & 14.85 & 13.90 & 13.47 & 12.90 & 12.12 \\
\hline \multirow{5}{*}{$p H$} & $160^{\circ} \mathrm{C}$ & 12.30 & 11.53 & 11.12 & 10.98 & 10.89 & 10.85 \\
\hline & $165^{0} \mathrm{C}$ & 11.80 & 11.43 & 11.14 & 10.92 & 10.84 & 10.55 \\
\hline & $170^{0} \mathrm{C}$ & 11.91 & 11.63 & 11.10 & 10.74 & 10.66 & 10.56 \\
\hline & $175^{0} \mathrm{C}$ & 11.73 & 11.33 & 10.86 & 10.74 & 10.60 & 10.36 \\
\hline & $180^{\circ} \mathrm{C}$ & 11.50 & 11.12 & 10.80 & 10.64 & 10.47 & 10.29 \\
\hline \multirow{5}{*}{ Dissolved carbohydrates \% } & $160^{\circ} \mathrm{C}$ & 25.92 & 26.59 & 27.71 & 28.95 & 30.12 & 31.00 \\
\hline & $165^{0} \mathrm{C}$ & 26.40 & 27.94 & 29.00 & 30.54 & 31.46 & 31.70 \\
\hline & $170^{\circ} \mathrm{C}$ & 28.91 & 29.18 & 30.78 & 32.53 & 32.87 & 34.15 \\
\hline & $175^{0} \mathrm{C}$ & 28.49 & 31.00 & 32.05 & 33.15 & 33.71 & 32.67 \\
\hline & $180^{\circ} \mathrm{C}$ & 30.12 & 31.18 & 33.27 & 34.62 & 34.74 & 37.32 \\
\hline \multirow{5}{*}{ Dissolved lignin \% } & $160^{\circ} \mathrm{C}$ & 78.60 & 79.80 & 81.10 & 81.40 & 82.90 & 83.90 \\
\hline & $165^{\circ} \mathrm{C}$ & 79.30 & 80.30 & 81.55 & 82.85 & 83.25 & 84.40 \\
\hline & $170^{\circ} \mathrm{C}$ & 80.15 & 82.10 & 83.35 & 84.10 & 84.55 & 85.50 \\
\hline & $175^{0} \mathrm{C}$ & 80.75 & 83.85 & 84.25 & 85.00 & 85.75 & 86.75 \\
\hline & $180^{\circ} \mathrm{C}$ & 82.50 & 83.85 & 85.40 & 86.60 & 87.45 & 88.35 \\
\hline
\end{tabular}

Volume 5 Issue 2, February 2016

www.ijsr.net 


\section{International Journal of Science and Research (IJSR) \\ ISSN (Online): 2319-7064}

Index Copernicus Value (2013): 6.14 | Impact Factor (2014): 5.611

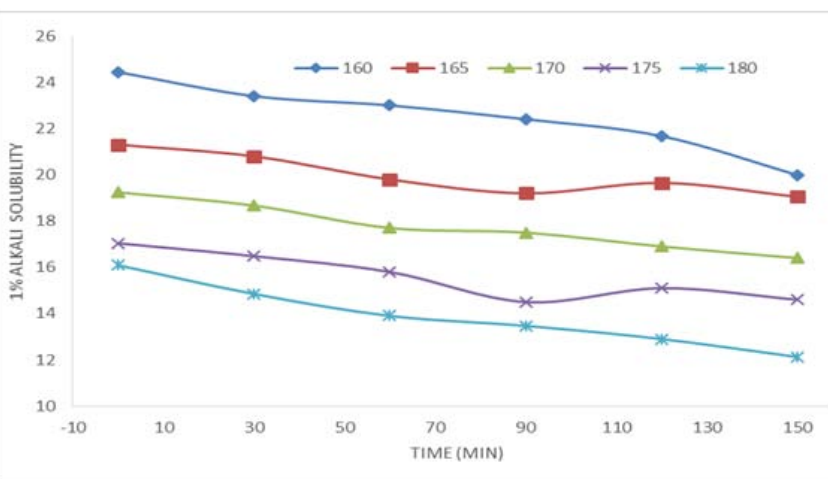

Figure 3: Effect of temperature and time of cooking on the $1 \%$ alkali solubility.

\subsection{Kinetics of Delignification}

The kraft delignification process is known to proceed in three distinct phases: initial, bulk and residual delignification. During the initial phase, which accounts for 20-25\% of the delignification, low molecular weight lignin and carbohydrates are dissolved. The initial phase lignin can be ignored in this work, as the initial cooking temperature is 160 ${ }^{0} \mathrm{C}$. The main delignification takes place during the bulk delignification phase, which starts at about $150{ }^{\circ} \mathrm{C}$ during which lignin is degraded as a result of the alkaline cleavage of the $\beta$-O-4 aryl ether linkages [25, 26]. The slow residual phase, which begins after about $92-94 \%$ delignification, is characterized by an increase in the amount of carbohydrates being dissolved with the lignin [17] due to cleavage of carbon-carbon bonds in lignin and - degradation [27]. Fig (4) shows the effect of time and temperature on the delignification process which is represented by lignin content and kappa no. where the relation between them is represented by the equation:

Klason lignin (insoluble lignin)=kappa number x 0.15 [T236]

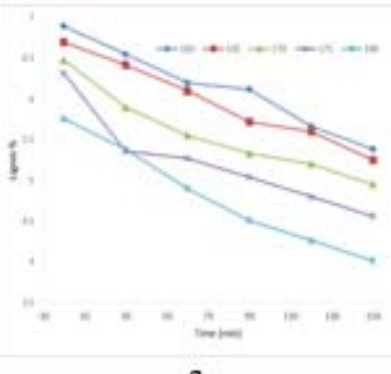

a

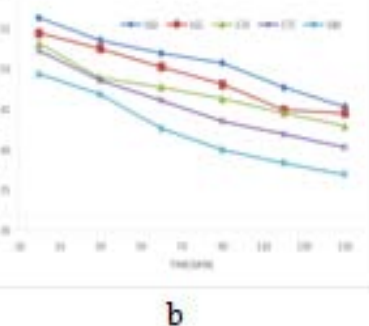

b
Figure 4: Effect of temperature and time of cooking on lignin (a) and kappa no. (b).

The delignification reactions are very temperature dependent. A small increase in temperature has a big effect on the delignification rate. The lignin content decreases as the time of reaction proceeds due to the degradation of lignin. While raising the temperature increased the rate of lignin dissolution. Since the delignification reactions are so rapid at high temperatures so, a few additional minutes will affect the quality of the pulp.
The activation energy $(\Delta \mathrm{E})$ is calculated from the reaction rate constants of kraft delignification using Arrhenius equation:

$$
K=(A) \exp \left(-E_{\alpha} / R T\right)
$$

Where $\mathrm{K}$ is the rate constant for the reaction, $\mathrm{A}$ the Arrhenius constant, Ea the activation energy for delignification (KJ mol $\left.{ }^{-1}\right)$, $\mathrm{R}$ the gas constant $\left(8.314 \mathrm{KJK}^{-1} \mathrm{~mol}^{-1}\right)$ and $\mathrm{T}$ is the absolute temperature (K). A plot of $\ln (\mathrm{K})$ versus $1 / \mathrm{T}$ should be a straight line with the slope equal to $\mathrm{Ea} / \mathrm{R}$ [27].

It seems that there is a transion point between the bulk and residual delignification phases in which the values of activation energy are 36.8 and -25.3 for bulk and residual phases, respectively. While $\Delta \mathrm{E}$ for the two phases is 14.8 $\mathrm{KJ} / \mathrm{mol}$. This value is too low may be because the $\mathrm{NaOH}$ ionizes in solution into $\mathrm{Na}^{+}$and $\mathrm{OH}^{-}$ions, producing more $\mathrm{OH}^{-}$ions which may act as an auto catalyst [28]. Consequently, it will deactivate the energy required for the delignification reaction. It is anticipated that the activation energy depends on both the chemical and physical structure of the wood. For this reason the activation energy are different from different studies [15]. On the other hand, the activation energy of holocellulose showed a value of 39.06 $\mathrm{KJ} / \mathrm{mol}$ due to the degradation of polysaccharides, which begins through the heating period and continue to the end of cooking.

\subsection{Pulping Selectivity}

Pulping selectivity is the ratio between dissolved lignin and dissolved carbohydrates [13] (Fig.5). The selectivity data are compiled in Table (3) and graphically represented in Fig (6).

Table 3: The selectivity data of kraft pulp samples.

\begin{tabular}{|c|c|c|c|c|c|}
\hline Time (min) & $160^{\circ} \mathrm{C}$ & $165^{\circ} \mathrm{C}$ & $170^{\circ} \mathrm{C}$ & $175^{\circ} \mathrm{C}$ & $180^{\circ} \mathrm{C}$ \\
\hline 0 & 3.03 & 3.00 & 2.77 & 2.83 & 2.74 \\
\hline 30 & 3.00 & 2.87 & 2.81 & 2.70 & 2.69 \\
\hline 60 & 2.93 & 2.81 & 2.71 & 2.63 & 2.57 \\
\hline 90 & 2.81 & 2.71 & 2.59 & 2.56 & 2.50 \\
\hline 120 & 2.75 & 2.65 & 2.57 & 2.54 & 2.52 \\
\hline 150 & 2.71 & 2.65 & 2.50 & 2.66 & 2.37 \\
\hline
\end{tabular}

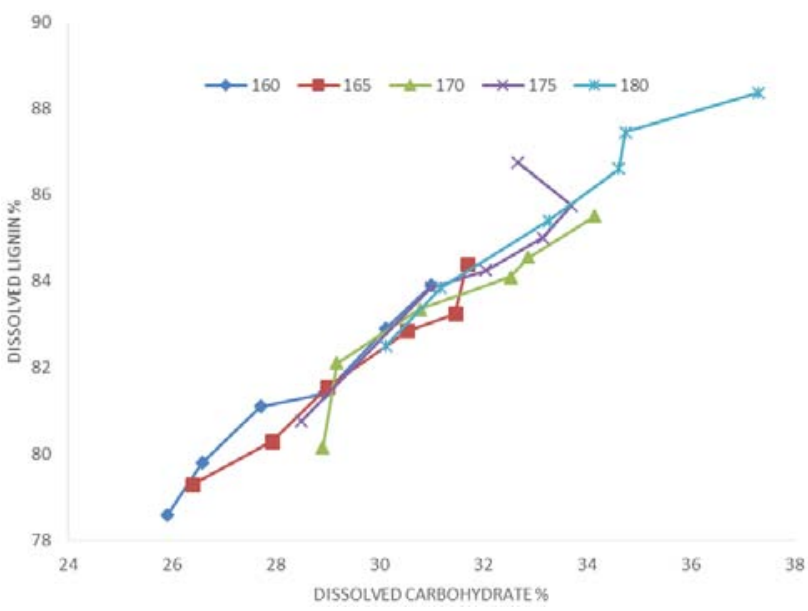

Figure 5: The relation between dissolved lignin \% and dissolved carbohydrates \%. 


\section{International Journal of Science and Research (IJSR) \\ ISSN (Online): 2319-7064}

Index Copernicus Value (2013): 6.14 | Impact Factor (2014): 5.611

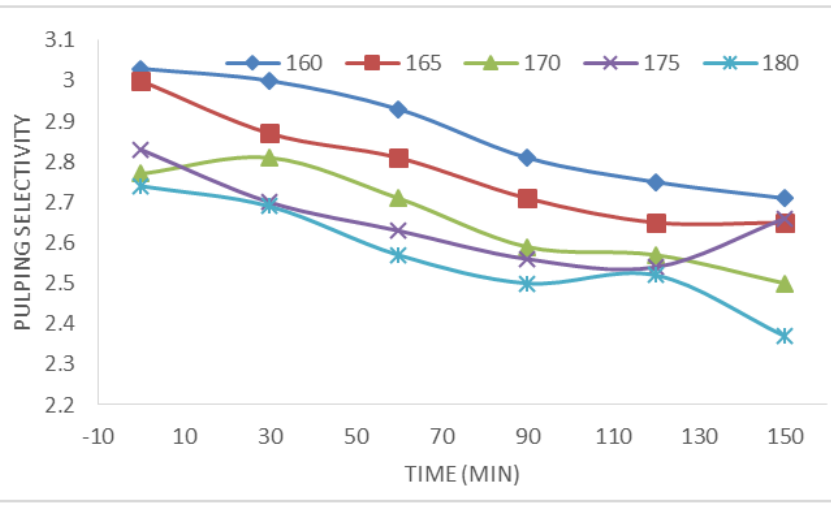

Figure 6: The relation between pulping selectivity and time of cooking.

Most of the dissolved lignin and degraded carbohydrates occurred at the heating period while cooking at the elevated temperatures degraded bagasse components with lower ratio. On the other hand, the carbohydrate loss is almost equal the dissolution of lignin through the cooking time $(0-150 \mathrm{~min})$ at $160-175{ }^{\circ} \mathrm{C}$ while at $180{ }^{\circ} \mathrm{C}$, the degraded polysaccharides is higher than dissolved lignin because the rate of reaction is very high. The selectivity of delignification decreases by increasing the temperature and time may be because lignin becomes inaccessible to alkaline degradation; while the rate of degradation becomes faster.

\section{Conclusion}

Bagasse pulp is perceived to be an inferior replacement for wood pulp because it gives higher yield and lower lignin content. Bagasse pulping is strongly affected by temperature and time of cooking. Kinetics of kraft pulping is very important to explore the nature of process and determine the rate of reaction as well as the activation energy. Over $175{ }^{\circ} \mathrm{C}$ is non selective temperature for kraft pulping of Egyptian bagasse. There is a transition point between bulk and residual phase of delignification (probably after $90 \mathrm{~min}$ at elevated temperature). The activation energy for bulk and residual phases is very low $(14.8 \mathrm{KJ} / \mathrm{mol})$ due to the autocatalytic effect of $\mathrm{NaOH}$ while the activation energy of holocellulose is $39.06 \mathrm{~kJ} / \mathrm{mol}$. The carbohydrate loss is almost equal the dissolution of lignin through the cooking time (from 0 to 150 min) at $160-175{ }^{0} \mathrm{C}$ while at $180{ }^{\circ} \mathrm{C}$ the degradation of polysaccharides is higher than lignin dissolution. The selectivity of delignification decreases by increasing the temperature and time of kraft pulping.

\section{References}

[1] H. Zuqiang, L. Xingtang, H. Huayu ,G. Li, C. Yongjun, T. Zhangfa, "Influence of mechanical activation on the graft copolymerization of sugarcane bagasse and acrylic acid," Polymer degradation and stability, 94, pp. 17371745, 2009.

[2] C.F. Liu, J. L Ren, F. Xu, J.S. Liu, Sun J. X, R.C. Sun, " Isolation and characterization of cellulose obtained from ultrasonic irradiated sugarcane bagasse," J. Agr. Food Chem, 54 (16), pp. 5742-5748, 2006.

[3] E. Gonzalo, C.T. lindgren, M.E. lindstrom, "Kinetics of wheat straw delignification in soda and kraft pulping,"
Journal wood chemistry and technology, 18 (1), pp. 6982, 1998.

[4] M. Neureiter, H. Danner,C. Thomasser, B. Saidi, R. Braun, "Dilute-acid hydrolysis of sugarcane bagasse at varying conditions," Appl. Biochem. Biotech, 49, pp.98100, 2002.

[5] J. X. Sun, X. F. Sun, R. C. Sun, Y. Q. Su, "Fractional extraction and structural characterization of sugarcane bagasse hemicelluloses," Carbohydrate polymer, 56 (2), pp.195-204, 2004.

[6] P. F. Vena, M. P. Garcia- Aparicio, M. Brienzo, J. F. Gorgens, T. Rypstra, "Impact of hemicelluloses preextraction on pulp properties of sugarcane bagasse," Cellulose chemistry and Technology, 47 (5-6), pp. 425441, 2013.

[7] Y. Ling, L. Shijie, "Kinetic model for kraft pulping process,” Ind. Eng. Chem Res., 44, pp.7078-7085, 2005.

[8] J. R. Obst, "Kinetics of kraft pulping of a middlelamella- enriched fraction of loblolly pine," Tappi journal, 68(2), pp.100-104, 1985.

[9] E. Sjostrom, "Wood chemistry fundamentals and application," Academic press, Inc, New-York, pp. 127 128, 1981.

[10] A. A. Shatalov, P. Helena, "Kinetics of polysaccharide degradation during ethanol- alkali delignification of giant reed-part 2. Minor carbohydrates and uronic acids," Carbohydrate polymers, 61, pp. 304-313, 2005.

[11] K. L. Nguyen, V. Q. Dang, "The fractal nature of Kraft pulping kinetics applied to thin eucalyptus nitens chips," Carbohydrate polymers, 64, pp. 104-111, 2006.

[12]L. E. Wise, Wood chemistry. Vol. 1-2, Reinhoid publishing corporation, New York, p.36, 1952.

[13] M. B. Ghazy, M. S. Thabet, F. Abdel-Hai, M. E. Owda, "Modification of Egyptian bagasse kraft pulping using yield-increasing additives. I-Effect on chemical properties,” Egypt J. chem., 57 (5, 6), 447-462, 2014.

[14]A. V. Tran, "Chemical analysis and pulping study of pineapple crown leaves," Industrial crops and products, 24, pp.66-74, 2006.

[15] T. J. Rainey, N. B. Clark, “An overview of bagasse as a resource for the Australian paper industry," Proc. Aust soc. Sugarcane technol., 26,226, 2004.

[16] V. Dang, K. L. Nguyen, "Characterization of the heterogeneous alkaline pulping kinetics of hemp woody core," Bioresource technology, 97, pp. 1353-1359, 2006.

[17] M. Takanori, S. Hirotaka, "Improvement of pulp strength and yield by computer simulation of lo-solids kraft cooking," Tappi journal, 84(6), 65, 2001.

[18]D. Vaaler, "Yield increasing additives in kraft pulping: effect on carbohydrates retention, composition and handsheet properties," Ph.D. Thesis, Norwegian university of science and technology, Norweg, 2008.

[19] V. Costanza, F. M. Rossi, P. Costnanza, "Diffusion and reaction in isothermal pulping digesters," Ind. Eng. Chem. Res., 40(18), pp.3965-3972, 2001.

[20]H. Sixta, Handbook of pulp.vol.1, Copyright C willeyVch Verlag GmbH \& Co.KGaA, Weinhein. P.120, 2006.

[21]A. A. Shatalov, P. Helena, "Kinetics of polysaccharide degradation during ethanol-alkali delignification of giant reed - part 1. Cellulose and xylan," carbohydrate polymers, 59, pp. 435-442, 2005.

\section{Volume 5 Issue 2, February 2016}


[22] M. Gustavsson, "The significance of liquor-to-wood ratio on the reaction kinetics of spruce sulphate pulping," master of science in chemical engineering, Karlstads University, Karlstad, 2007.

[23] G. J. Kubes, B. I. fleming, J. M. Macleod, H. I. Bolker, D. P. Werthermann, "Viscosities of unbleached alkaline pulps. II. The G- factor," Journal of wood chemistry and technology, 3(3), pp.313-333, 1983.

[24] P. Matheus, P. Vinicios, Z. Mara , J. Z. Ademir, "Crystalline properties and decomposition kinetics of cellulose fibers in wood pulp obtained by two pulping processes," Polymer degradation and stability, 96,pp.679-685,2011.

[25] J. M. Willis, N. R. Jagannathan, F.G. Herring, "The potential of $13 \mathrm{C} \mathrm{Cp} / \mathrm{Mas} \mathrm{Nmr}$ in the study of kraft pulping kinetics," Journal of wood chemistry and technology, 6(2), pp.249-267,1986.

[26] J. Gierrer, "The reactions of lignin during pulping," Svensk papperstidn, 73, pp. 571-596, 1970.

[27] J. Gominho, P. Helena, "Influence of raw- material and process variables in the kraft pulping of Cynara cardunculus L," Industrial crops and products, 24, pp.160-165, 2006.

[28] P. Matthews , "Advanced chemistry, low price edition, Cambridge university press, United Kingdom, chapter 78, P. 465,1996. 